\title{
APROXIMAÇÃO ENTRE CRIANÇA E LEITURA: O USO DE HISTÓRIAS EM QUADRINHOS COMO RECURSO DIDÁTICO PARA O ENSINO FUNDAMENTAL
}

\author{
Ruth Braga Aguiar ${ }^{\mathrm{i}}$ \\ Alan de Souza Prazeres ${ }^{\text {ii }}$
}

\begin{abstract}
Resumo: Objetiva-se com este trabalho apresentar uma metodologia do uso de HQ aplicada no ensino fundamental, sendo este um atraente gênero textual que o professor dispõe para incentivar o hábito e o prazer pela leitura. Para isso, baseou-se, principalmente, em Campos e Lomblogia, PCN, PROFORMAR e Freire, que colocam os pontos positivos no uso de HQ como recurso de ensino e o incentivo à leitura. Constata-se que: a) o uso desse gênero textual em sala de aula requer do professor formação sólida; b) as HQ possuem características únicas que atraem e conquistam seus leitores; e c) sua utilização na escola e no processo de incentivo à leitura requer do professor: compromisso com as práticas pedagógicas, domínio desse gênero, planejamento e criatividade.
\end{abstract}

Palavras-chave: Leitura; Gêneros Textuais; Histórias em Quadrinhos; Formação de Docente.

\section{APROXIMACIÓN ENTRE NIÑO Y LECTURA: EL USO DE LAS HISTORIETAS COMO RECURSO DIDÁCTICO PARA LA ENSEÑANZA FUNDAMENTAL}

Resumo: Se pretende con este trabajo presentar una metodología del uso de HQ aplicada en la enseñanza fundamental, siendo éste un atractivo género textual que el maestro dispone para incentivar el hábito y el placer por la lectura. Para ello, se basó principalmente en: Campos y Lomblogía, PCN, PROFORMAR y Freire que sitúan los puntos positivos en el uso de HQ como recurso de enseñanza y el incentivo a la lectura. Se constata que: a) el uso de ese género textual en el aula requiere del profesorado formación sólida; B) las HQs tienen características únicas que atraen y conquistan a sus lectores; y c) su utilización en la escuela y en el proceso de incentivo a la lectura requiere del profesorado: compromiso con las prácticas pedagógicas, dominio de ese género, planificación y creatividad.

Palabras clave: Lectura; Géneros textuales; Historietas; Formación docente.

\section{Introdução}

Buscando uma relação entre a teoria e a prática, este trabalho surgiu como resultado final da disciplina Prática de Ensino, do curso de Licenciatura em Letras da Universidade Federal do Amazonas, Campus Humaitá. Sendo um dos objetivos da disciplina discutir e pensar 
meios para ensino da leitura e literatura, as aulas no curso de Letras foram direcionadas para elaboração e para aplicação de projetos de ensino e incentivo à leitura.

Esta relação entre teoria acadêmica e prática, além de viabilizar o aprendizado, deriva das transformações decorridas pela sociedade atual, passando a estabelecer, entre o conhecimento acadêmico adquirido e a prática, aplicabilidade exigida pelo mundo do trabalho.

Neste sentido, a viabilização do ensino através da visualização da teoria em prática, bem como o incentivo à leitura para novos leitores, provocou a discussão sobre histórias em quadrinhos no contexto escolar, motivada por vários aspectos, entre eles: a) são aceitas com maior entusiasmo pelos alunos por mostrarem situações cotidianas desses e acabam sendo um eficaz instrumento nas atividades de leitura; b) aumentam a motivação dos estudantes para exercitarem o hábito da leitura por ser um gênero com peculiaridades: possuem muitas cores, expressões, frases curtas e outros aspectos que podem facilmente ser compreendidos pelos leitores e; c) ser um dos gêneros mais comuns entre crianças que começam a ler. Com essas afirmativas, observou-se a necessidade de discutir essa temática, sobretudo por esse gênero possuir maior aceitação por parte dos alunos que estão em processo inicial do hábito da leitura (público-alvo desta discussão), bem como por ser aliado ao hábito da leitura e também de ensino.

Entretanto, é imprescindível que o professor, durante sua formação, se aproprie de conhecimentos que o levem a práticas de incentivo à leitura no momento de sua atuação dentro de sala de aula. Nesse sentido, o gênero textual histórias em quadrinhos contribui para o hábito da leitura e para o trabalho com temas transversais, sendo, de acordo com o Menezes (2001):

Segundo o Ministério da Educação (MEC) são temas que estão voltados para a compreensão e para a construção da realidade social e dos direitos e responsabilidades relacionados com a vida pessoal e coletiva e com a afirmação do princípio da participação política. Isso significa que devem ser trabalhados, de forma transversal, nas áreas e/ou disciplinas já existentes. (s/p)

Os temas transversais, nesse sentido, correspondem a questões importantes, urgentes e presentes sob várias formas na vida cotidiana. Com base nessa idéia, o MEC definiu alguns temas que abordam valores referentes à cidadania: Ética, Saúde, Meio Ambiente, Orientação Sexual, Trabalho e Consumo e Pluralidade Cultural. No entanto, os sistemas de ensino, por serem autônomos, podem incluir outros temas que julgarem de relevância social para sua comunidade. 
Para que se tenha um aluno crítico-reflexivo, é necessário que o aluno tenha contanto com diversos gêneros textuais, incluindo o gênero em discussão. O contato com esse, na maioria das vezes, acontece no âmbito familiar, por motivos acima apontados. Mas a análise da linguagem e o incentivo ao hábito da leitura que ele traz consigo somente será bem-sucedido quando mediado por professor em sala de aula.

Com isso, o presente relato de experiência apresenta discussões pertinentes sobre as práticas de leituras com o professor na sala de aula e o porquê de HQ no contexto escolar. Ao final desta pesquisa bibliográfica, é sugerida uma proposta de trabalho com o uso do referido gênero em sala de aula, para o incentivo à leitura de outros e mais densos gêneros textuais.

\section{Metodologia}

Considerando que esta experiência partiu de debates sobre teorias voltadas a formação docente e sobre o ensino da leitura, isto nas aulas do curso de Letras, na disciplina Prática de Ensino, observou-se aqui uma pesquisa teórica e uma pesquisa-ação; está última porque, posteriormente, houve aplicação do projeto numa turma do $5^{\circ}$ do ensino fundamental.

A pesquisa teórica serviu de base para a discussão sobre a formação de docentes e suas práticas, visando, além da proficiência na leitura, o desenvolvimento pelo gosto da mesma, como recomenda os Parâmetros Curriculares Nacionais,

Após o estudo teórico, partiu-se para a pesquisa-ação, que se caracteriza pela relação próxima entre o pesquisador e o grupo investigado; no caso deste estudo, pelo futuro docente com os alunos do ensino fundamental. A opção por essa abordagem se explica no que diz Fonseca (2002):

O pesquisador quando participa na ação traz consigo uma série de conhecimentos que serão o substrato para a realização da sua análise reflexiva sobre a realidade e os elementos que a integram. A reflexão sobre a prática implica em modificações no conhecimento do pesquisador (p. 35).

Neste sentido, aplicar de forma prática o conhecimento teórico adquirido durante o curso de graduação corrobora com a formação do futuro docente, pois agrega conhecimento e reflexão ao ver a teoria em ação. 
Assim, após o aprofundamento teórico e o desenvolvimento do projeto, a pesquisa continuou e se aprimorou na aplicação do projeto no ambiente próprio: a sala de aula do $5^{\circ}$ ensino fundamental.

\section{As práticas de leitura e o professor em sala de aula}

O educador que obtém boa formação certamente terá o compromisso com a aprendizagem de seus alunos, organizando situações que desenvolvam nos mesmos a criticidade e a reflexão sobre diferentes assuntos. Assim, o docente deve proporcionar que o educando tenha contato com as mais diversas situações de reflexão para a construção de conhecimentos e ideias das mais variedades temáticas.

Freire (1996 p. 29) nos diz que enquanto ensino, continuo buscando, reprocurando [...] pesquiso para conhecer o que ainda não conheço e comunicar ou anunciar a novidade. Nesse sentido, o professor deve sempre pesquisar formas de mostrar aos alunos novas possibilidades de reflexão e crítica, procurando despertar o gosto pela leitura e a habilidade da mesma.

Os PCNs (1998, p. 48) ressaltam que ao organizar as formas de ensino, é necessário ter instrumentos que possibilitem e desenvolvam a capacidade discursiva dos alunos, nos quesitos de escuta, leitura e produção de textos. Por isso, deve-se se planejar método de ensino que desenvolva a escuta e a oralidade, sendo para isso imprescindível a leitura.

Nesse sentido, o professor deve levar os alunos às práticas de leitura que desenvolvam seus próprios discursos, com sua própria linguagem, mostrando sua capacidade de organização de pensamento e opinião, pois sabemos que a apropriação da linguagem é necessária para discutir, debater, opinar, dialogar, sendo essa adquirida somente através do hábito da leitura. De acordo com os PCNs (1998 p. 41):

A leitura é um processo no qual o leitor realiza um trabalho ativo de compreensão e interpretação do texto, a partir de seus objetivos, de seu conhecimento sobre o assunto, sobre o autor, de tudo o que sabe sobre a linguagem etc. Não se trata de extrair informação, decodificando letra por letra, palavra por palavra. Trata-se de uma atividade que implica estratégias de seleção, antecipação, inferência e verificação, sem as quais não é possível proficiência. 
Nesse sentido, a leitura chamada por Freire de leitura de mundo é um processo contínuo que começa no berço, nos primórdios das operações cognitivas ao longo de toda a vida. A leitura de mundo é algo comum a todos. Essa, por sua vez, nos ensina a ler além do que está impresso, escrito, desenhado no papel; ensina-nos a ler além dos sinais gráficos que dizem Eva viu a uva (FREIRE apud GADOTTI,1996). Há toda uma leitura de mundo além da leitura da palavra. A habilidade da leitura do mundo é subjetiva e aproxima o leitor do texto, tentando esse decifrar os códigos daquele. Essa leitura de mundo vem antes da leitura da palavra e deve a ela ser somada.

Por a leitura ser o principal caminho para se chegar à competência linguística, necessária para tornar-se cidadão crítico, o educador pode ter como auxiliar, para incentivar o hábito da leitura, o gênero textual Histórias em Quadrinhos que, como colocado anteriormente, chama atenção e faz parte do cotidiano infanto-juvenil.

\section{Histórias em Quadrinhos? Por quê?}

O gênero discursivo "Histórias em Quadrinhos" nasceu nos Estados Unidos, no século XIX durante a Segunda Guerra Mundial. A inicialmente popularidade das HQ se deu devido a retratarem os heróis fictícios que venciam grandes confrontos e histórias que continham como temas crianças e fantasia. Após o término da grande guerra, outros temas surgiram para dar continuidade ao gênero, como terror e suspense.

Dentro desse hipergênero (HQ), tem-se os seguintes gêneros: a charge, caracterizada como um texto de humor que aborda algum fato ou tema ligado ao noticiário; o cartum, onde o humor advém de situações corriqueiras e cotidianas; a tira cômica, a qual é caracterizada por textos curtos, com personagens fixos ou não, com desfecho inesperado no final, atrelado ao humor; as tiras seriadas, as quais, como o próprio nome indica, cada capítulo diário interligado a uma trama maior que é cômica e seriada, usa elementos próprios, tais como: o desfecho inesperado e a história produzida em capítulos.

Para chegar à forma como conhecemos hoje, as HQs sofreram muitas influências, mas também se tornaram subsídios para diversas áreas como as artes, a comunicação e a educação. Sobre a HQ, Luyten (1984, p. 8) enfatiza que: 
Ao contrário do que muitos pedagogos apregoam, os quadrinhos exercitam a criatividade e a imaginação da criança quando bem utilizados. Podem servir de reforço à leitura e constituem uma linguagem dinâmica e adequada a nossa era fluída embora intensa e transitória, a fim de dar espaço permanente às formas de renovação. A influência (positiva ou negativa) deste poderoso meio de comunicação, que atinge principalmente o público infanto-juvenil, é um assunto muito sério, tendo em vista os altos índices de consumo.

No Brasil, para se referir à HQ são usadas expressões como "gibis", "historinhas" e "quadrinhos". No decorrer dos anos, surgiram muitas revistas do gênero, até que, em 1959, surge Maurício de Souza, que publica tirinhas de vários personagens que até hoje fazem sucesso. O sucesso acontece devido às histórias tratarem de situações e de personagens muito próximos da realidade das crianças; no caso da Turma da Mônica - mais conhecido trabalho de Souza -: a menina gulosa, a menina dentuça que bate nos amigos, a criança que troca o "l" pelo "r", - o chamado, rotacismo, fenômeno corrente na linguagem que, segundo Bagno (2007, p. 43), contribui na formação do português padrão - e tantos outros personagens criados para atraírem o público-alvo das historinhas.

Entretanto, sucesso entre o público infanto-juvenil e infantil, a leitura das Histórias em Quadrinhos, segundo Rama e Vergueiro (2008, p. 18):

[...] passou a ser estigmatizada pelas camadas ditas "pensantes", "cultas" da sociedade, pois acreditava-se que sua leitura afastava as crianças dos objetivos "mais nobres" - como o conhecimento do "mundo do livros" e o estudo de "assuntos sérios"-, que causavam prejuízos ao rendimento escolar e poderia, inclusive, gerar consequências ainda mais aterradoras, como o embotamento do raciocínio lógico, a dificuldade para a apreensão de idéias abstratas e o mergulho em um ambiente imaginativo prejudicial ao relacionamento social e afetivo de seus leitores.

Por muito tempo, a leitura de HQs era considerada como "passatempo" ou "leitura superficial", devido aos diversos aspectos metalinguísticos que o gênero possui, pois há um entrelaçamento de escrita (informação percebida) e imagens (informações recebidas). Logo, este gênero foi alvo de concepções errôneas sobre sua significação e, por muito tempo, considerado inapropriado para ser trazido para dentro da sala de aula.

Contudo, de acordo com os PCNs (2000, p.128), as Histórias em Quadrinhos é um gênero discursivo adequado para o trabalho com a linguagem escrita, sendo, inclusive, inserido em livros didáticos como recurso adicional à aprendizagem de vários temas transversais. De acordo com Luyten (1984), existem diversas possibilidades de trabalho com 
HQs em sala de aula. Inicialmente, pode-se tratar sobre os aspectos: das formas, das representações das expressões físicas dos personagens. O dinamismo na ação da história, a representação e apresentação da realidade e os conteúdos também podem ser trabalhados se a historinha mostrar personagens-tipos conhecido dos leitores, como: familiares (pai, mãe), profissionais (médicos, operários), sociais (ricos, pobres, marginais), culturais (como é vista a família, a arte, a juventude, a velhice) e outros inúmeros aspectos.

Como nos mostram Rama e Vergueiro (2008, p. 35), os quadrinhos são constituídos por meio de uma imagem fixa, de um instante específico ou de uma sequência interligada de instantes, que são essenciais para a compreensão de uma determinada ação ou acontecimento. Pode-se também analisar as ações contínuas, sequenciadas uma às outras, em um dado recorte temporal, as quais refletem determinado momento sócio-histórico.

Por isso, o referido gênero pode ser aliado nas discussões de temas específicos, conforme as atitudes dos personagens e sistemas ideológicos. Ele também ajuda no ensino da linguagem oral e escrita e pela leitura. Por isso, elas são construídas, principalmente, para motivar a leitura nas crianças através do encantamento que provocam e, consequentemente, desperta na criança o prazer pela leitura, influenciando-a a ler outros gêneros textuais e a aumentar seus conhecimentos.

\section{Como trabalhar com histórias em quadrinhos na sala de aula: uma proposta}

Conforme Campos e Lomblogia (1984), as HQs são formas de expressão artística, constituídas por dois tipos de linguagem: a verbal e a não verbal. A verbal construída pelos textos, diálogos, pensamentos, onomatopeias ou até mesmo os balões. Já a não verbal é constituída pelas imagens, os quadros ou vinhetas, a paginação ou diagramação, o enquadramento e os personagens.

Para trabalhar com esse gênero como incentivo ao hábito da leitura, é imprescindível que o professor não permita que a aula se torne um momento apenas recreativo. É preciso escolher a história e planejar as atividades de modo a priorizar a compreensão do conteúdo, seja didático (gramático) ou social (temas transversais).

Os PCNs (2007) sugerem a HQ como gênero adequado para o trabalho de língua escrita, mas não fornece ao professor caminhos concretos para o trabalho com o mesmo. Por isso, a 
seguir, encontra-se uma proposta de trabalho planejada e discutida em um momento de formação docente.

\section{Metodologia de trabalho com HQ}

[História em Quadrinhos: A Turma da Mônica - Tempo estimado por encontro: 45 min]

- $1^{\circ}$ momento: Contato com o gênero

Iniciar com uma conversa sobre a leitura de gibis: quais personagens se identificam ou gostam, o que mais gosta nos gibis etc. Nesse momento, deve-se levar para a sala de aula diversos gibis, proporcionando aos alunos um contato com as Histórias em Quadrinhos. A medição docente é essencial no modo de leitura, orientando a sequência de quadrinhos: da esquerda para a direita.

\section{- $2^{\circ}$ momento: Conhecendo a estrutura do gênero}

As HQ são narrativas feitas por imagens, que são acompanhadas por textos colocados em balões. Cada imagem, quadrinho ou vinheta representa uma ação. Cada balão representa uma de falar ou de pensar, por exemplo:

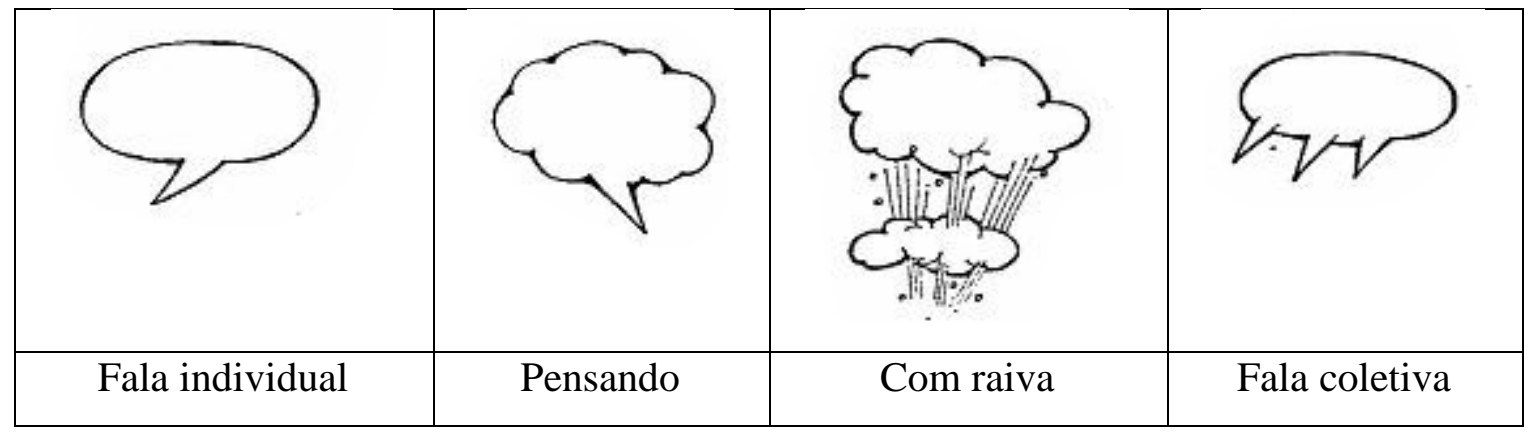

\section{Figura 1}

Fonte: www.maquinadequadrinhos.com.br

\section{- $3^{\circ}$ momento: A expressão das personagens}

Agora com mais intimidade com o gênero textual, o professor deve propor uma leitura individual, mas, antes, chamar a atenção para os gestos, as expressões faciais e as mudanças no tom de voz dos personagens pelo desenho das letras: quando em caixa alta, o personagem está gritando, e frases que terminam com exclamações, produzem sentido de grito. Após, propor que alguns alunos contem o que leram para a classe, poderão apontar as imagens do gibi para facilitar a exposição da sequência dos acontecimentos na história. 


\section{- $4^{\circ}$ momento: A descrição de personagens}

Após a leitura e releitura das HQs, propor aos alunos que observem as características das personagens, por exemplo: A Mônica usa um vestido vermelho, é dentuça e tem um coelhinho azul de pelúcia, é muito forte, amiga da Magali, é líder da turma, mas bate nos amiguinhos; o Cascão não gosta de tomar banho, tem medo da água e é amigo inseparável do Cebolinha etc. Deve-se orientar as crianças para que localizem valores positivos e negativos nas personagens, fazendo um balanço de sua personalidade. Para registrar esses dados, poderá ser feito, junto aos alunos, uma lista contendo as características positivas e negativas de cada personagem.

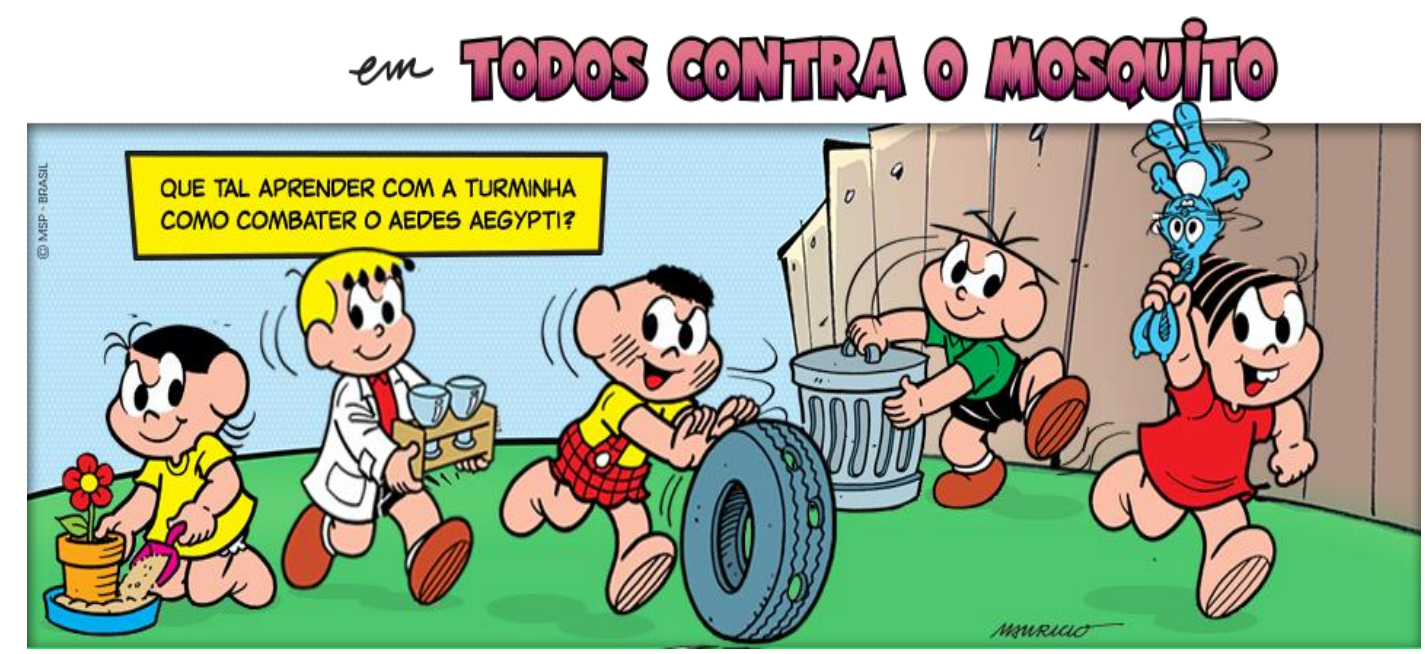

Figura 2

Fonte: http://turmadamonica.uol.com.br

\section{- $5^{\circ}$ momento: As onomatopeias}

As onomatopeias são sons representados por letras e desenhos. Deve-se explicar para alunos que, lendo essas expressões, eles poderão imaginar o som produzido por cada personagem. Isso faz parte também da linguagem não verbal.

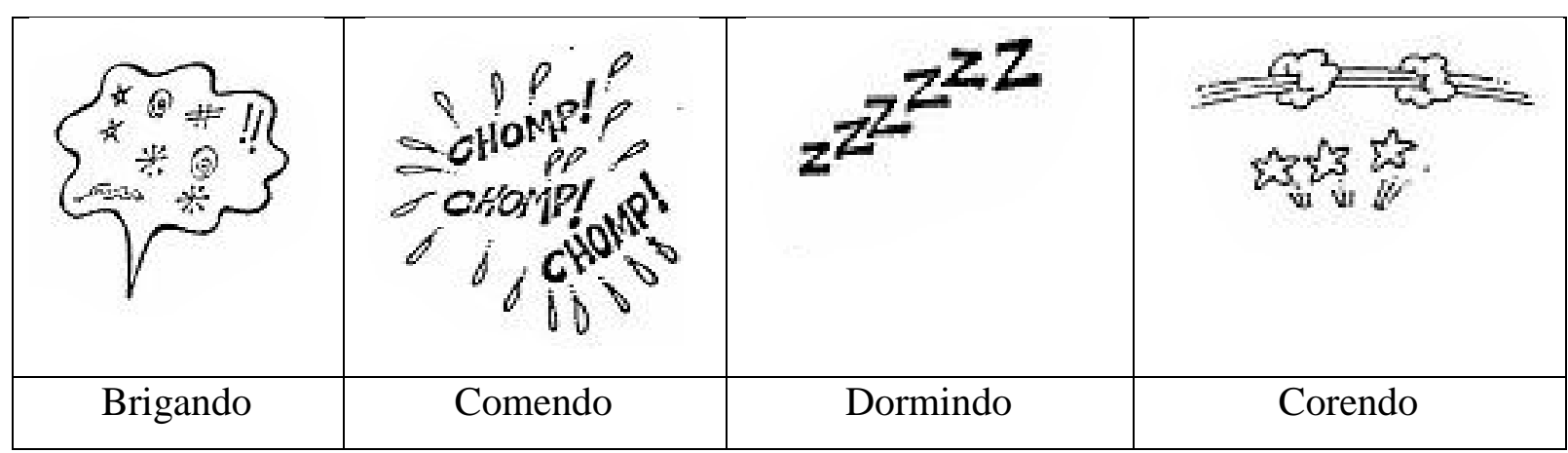

Figura 3

Fonte: www.maquinadequadrinhos.com.br 
- $6^{\circ}$ momento: Leitura oral

A leitura compartilhada é um ótimo recurso para o avanço do domínio da escrita. Para isso, deve-se dividir a classe em pequenos grupos ou pares de alunos e providenciar gibis para cada grupo. O aluno escolherá um episódio e ler para a classe, em voz alta e com ênfase na entoação das falas. Após o término da leitura, a tarefa é passada para a próxima criança, até que todos tenham lido.

\section{- $7^{\circ}$ momento: Marcadores do discurso direto}

Nos quadrinhos, os marcadores das falas das personagens são os balõezinhos. Nesse momento de leitura, os alunos deverão identificar a fala do narrador e a fala da personagem. Espera-se que os mesmos percebam que a fala da personagem está nos balões e a do narrador no canto do texto.

\section{- $8^{\circ}$ momento: Características da linguagem}

Selecionar gibis do Chico Bento e Cebolinha para a leitura pelos alunos. Após isso, pedir que identifiquem as palavras que Chico Bento e Cebolinha "falam errado". Com essa lista de "erros" será trabalhada a variação linguística, explicando que as falas das personagens têm muitos registros da linguagem oral e regional. Quanto à linguagem regional, pedir aos alunos que identifiquem marcas da região rural. Em relação aos aspectos ortográficos, explicar que a escrita depende de uma convenção, que é a ortografia, criada para unificá-la e facilitar o entendimento do que se lê. Com um trabalho em duplas, desafiar os educandos a localizarem e corrigirem os "erros" ortográficos. Podendo consultar o dicionário, se necessário.

\section{- $9^{\circ}$ momento: A linguagem verbal e não verbal}

Depois da leitura de um quadrinho, mostra e exemplificar que: a) O texto verbal contém apenas palavras; b) $\mathrm{O}$ texto não verbal contém apenas desenhos, fotos ou outras imagens.

\section{- $10^{\circ}$ momento: Mostrar a relação imagem-fala}

Mostrar as relações existentes entre expressões faciais de cada personagem com a fala. 

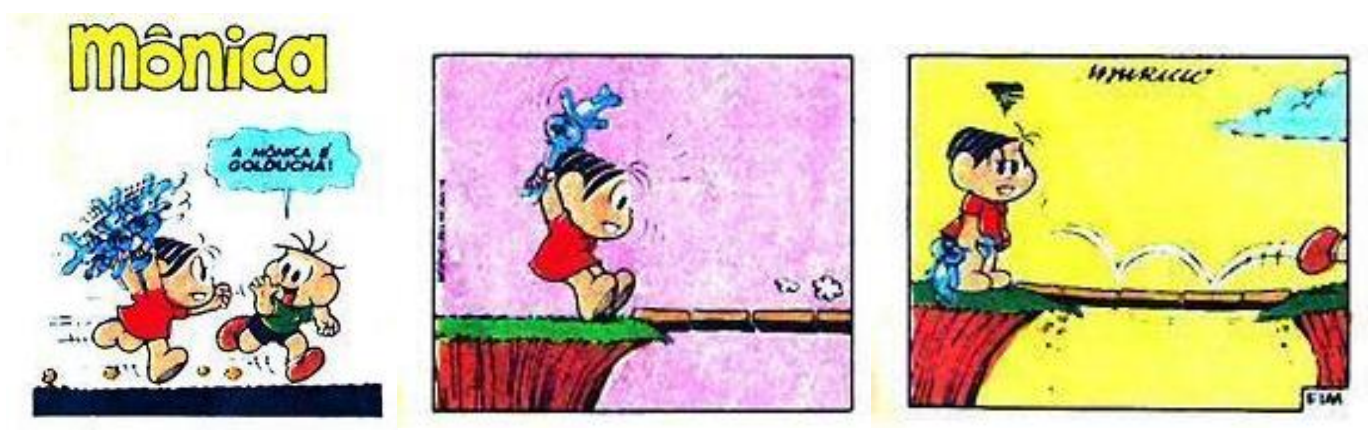

Figura 4

Fonte: www.maquinadequadrinhos.com.br

\section{- $11^{\circ}$ momento: Produção de Historia em Quadrinhos}

Ao final de todos os momentos explicativos sobre como se constitui uma História em Quadrinho, os alunos poderão produzir: ou um pequeno artigo de opinião sobre esse gênero ou uma própria história em quadrinhos, de forma simples, para que sejam expostas num momento de exposição. No caso da escolha por fazer a história, é válido desenhar, pintar e escrever as falas dos personagens.

\section{Reflexão sobre a recepção ao projeto de leitura e o trabalho do futuro docente}

A formação docente não se dá somente na sala de aula do ensino superior, mas também com experiências que coloquem em prática o conhecimento adquirido, discutido, pensando, aplicando-o e, em alguns momentos, repensando a abordagem e conteúdo. Durante a aplicação do projeto na escola, isto não é diferente.

No que se refere a observação da formação do futuro docente, durante os dias da aplicação do projeto de leitura, os graduandos puderam observar e praticar o domínio de turma, criando estratégias para que os alunos do $5^{\circ}$ ano mantivessem a atenção, ora ofereciam um prêmio (bombom) para quem participasse positivamente, ora os instigavam a fazer relação com o próprio conhecimento de mundo. Ainda, no que se refere aos futuros docentes, os mesmos traziam à professora-orientadora sentimentos de alegria a cada avanço em sala de aula, mas também sentimentos de angústias a cada dificuldade encontrada, bem como à incerteza de que se realmente queriam, no futuro, estar à frente de uma turma, visto à realidade da sala de aula. Este momento era de reflexão sobre políticas de incentivo à educação no que tange ao oferecimento de uma estrutura e recurso adequados ao ensino e de uma política de valorização docente. 
Sobre a observação da aceitação do projeto pelo $5^{\circ}$ ano, no último encontro, num total de 5 dias corridos, houve a exposição dos quadrinhos feitos pelos próprios alunos; curtos, em forma de tirinhas, confeccionados em papel A4 e expostos nos corredores da escola. Posteriormente, eles apresentavam, orgulhosos, o trabalho aos alunos da escola que visitaram a exposição.

A turma, com 30 alunos e com a agitação característica própria da idade, ficou feliz em ter na escola contato com algo que não parecia um "livro sério", mas algo que se podia ver na TV. Em alguns casos, diante da novidade de que poderia estar se divertindo e aprendendo ao mesmo tempo, houve dúvidas de que se realmente estivesse acontecendo um momento de aprendizagem. Por isso, em alguns momentos, conter a alegria e a vontade da turma de ter acesso a todos os gibis ao mesmo tempo, sem terminar a leitura de um, foi também um aprendizado para os futuros docentes.

Outro momento interessante e que mostra a identificação do aluno do $5^{\circ}$ ano, bem como o despertar do gosto pela leitura e pelo compartilhamento da mesma, foi quando eles começaram a levar os gibis que tinham em casa ou que encontraram na sala de leitura da escola e, uns poucos que tinham mais condições, pediram aos pais para comprar.

\section{Considerações finais}

Vivemos numa sociedade repleta de necessidades, entre elas as intelectuais, exigidas de quem deseja possuir conhecimento. Essas necessidades intelectuais são suprimidas através da leitura. O hábito de ler é o caminho para o desenvolvimento intelectual do ser humano, tanto na esfera individual quanto coletiva. No processo de ensino e aprendizagem é fundamental confrontar o discente a inúmeras possibilidades de aquisição de repertório e de desenvolvimento do pensamento.

Por isso, buscar recursos que despertem o interesse pela leitura deve ser algo desafiador e constante. Nesse sentido, as Histórias em Quadrinhos, quando trabalhada em sala de aula por um docente que teve uma formação prática e orientada para a pesquisa de novos métodos, será instrumento de aquisição do hábito e gosto pela leitura, muitas vezes estereotipada por muitos como "chata" e "dispensável". 


\section{Referências}

BAGNO, Marcos. Preconceito linguístico. São Paulo: Editora Loyola, 2007.

BRASIL, Ministério da Educação e Desporto. Parâmetros Curriculares Nacionais - Língua Portuguesa $-5^{\text {a }}$ a $8^{\text {a }}$ Séries. Brasília, 2000.

BRASIL, Ministério da Educação e Desporto. Parâmetros Curriculares Nacionais - Língua Portuguesa $-5^{\text {a a }} 8^{\text {a }}$ Séries. Brasília, 1998.

CAMPOS, M. de F. H; LOMBLOGIA, R. HQ: uma manifestação de arte. In: LYTEN, Sônia M. B. (org). Histórias em quadrinhos: leitura crítica. São Paulo: Paulinas, 1984.

MENEZES, Ebenezer Takuno de; SANTOS, Thais Helena dos. Verbete temas transversais. Dicionário Interativo da Educação Brasileira - Educabrasil. São Paulo: Midiamix, 2001. Disponível em: <http://www.educabrasil.com.br/temas-transversais/>. Acesso em 30 de set. 2017.

FONSECA, J. J. S. Metodologia da pesquisa científica. Fortaleza: UEC, 2002. Apostila.

FREIRE, Paulo. Pedagogia da autonomia: saberes necessários à pratica educativa. Paulo Freire. São Paulo: Paz e Terra, 1996.

GADOTTI, Moacir. Paulo Freire: Uma Biobibliografia, São Paulo, 1996.

LUYTEN, Sonia M. Bibe. HQ como Prática Pedagógica. In: Histórias em quadrinhos: leitura crítica. São Paulo: Paulinas, 1984a.

VERGUEIRO, Waldomiro. A linguagem dos quadrinhos: uma "alfabetização" necessária. In: RAMA, Ângela; VERGUEIRO, Waldomiro. (orgs). Como usar as histórias em quadrinhos na sala de aula. 4. ed. São Paulo: Contexto, 2010.

\footnotetext{
${ }^{\text {i } U n i c a r i o c a, ~ I n s t i t u t o ~ N a c i o n a l ~ d e ~ E d u c a c ̧ a ̃ o d ~ e ~ S u r d o s . ~}$

ii Mestrando em Letras da Universidade Federal de Rondônia.
} 